\title{
A Review of Case-Based Decision Theory
}

\author{
Shiye Hu \\ School of Business Administration, South China University of Technology, Guangzhou, China \\ Email: sayes.hu@foxmail.com
}

How to cite this paper: Hu, S.Y. (2019) A Review of Case-Based Decision Theory. American Journal of Industrial and Business Management, 9, 82-90. https://doi.org/10.4236/ajibm.2019.91007

Received: December 14, 2018

Accepted: January 8, 2019

Published: January 11, 2019

Copyright $\odot 2019$ by author(s) and Scientific Research Publishing Inc. This work is licensed under the Creative Commons Attribution International License (CC BY 4.0).

http://creativecommons.org/licenses/by/4.0/

\begin{abstract}
Case-Based Decision Theory (CBDT) is a method that achieves the tasks of making decisions by imitating the thinking mode of human beings and achieving relatively satisfying decisions with extremely limited information. It is one of the most representative methods of behavioral decision theory. In order to sort out CBDT systematically, this thesis presents the CBDT model and its evolution systematically, and perfectly reveals the current application fields of CBDT. This thesis also proposes the application prospect of CBDT in the field of venture capital on the basis of summarizing the current evaluation methods of venture capital projects.
\end{abstract}

\section{Keywords}

CBDT, Review, Model, Application, Venture Capital

\section{Introduction}

In the past 70 years, behavioral decision theory has experienced three stages of development: Expected Utility Theory, Non-Expected Utility Theory and Subjective Expected Utility Theory with Ambiguity [1]. It has formed a set of relatively perfect decision theory system. Its main approach is to make more satisfactory decisions under uncertain circumstances. Case-based Decision Theory (CBDT) is also a manifestation of behavioral Decision Theory. It uses the Expected Utility Theory (EUT) and the principle of Case-Based Reasoning (CBR) for reference, introduces the similarity function of CBR and the utility level of EUT. In the process of decision-making, CBDT better imitates the way of human thinking, that is, decision-makers make decisions based on past experiences or similar situations on the cases they are facing at present. It doesn't require hypothetical reasoning, but requires the decision maker to be aware of the cases he has encountered and the utility value of the results. Moreover, it is able to make relatively satisfactory decisions with extremely limited information, which 
is the biggest characteristic that distinguishes from any other methods.

Although there are many literatures applying CBDT at present, there are very few literatures systematically sorting out CBDT, which is not conducive to the spread, development and innovation of this theory. Therefore, this thesis presents the CBDT model and its evolution systematically, and perfectly reveals the current application fields of CBDT. This thesis also proposes the application prospect of CBDT in the field of venture capital on the basis of summarizing the current evaluation methods of venture capital projects.

\section{CBDT Model and Its Evolution}

CBDT first appeared in Discussion Paper of Gilboa and Schmeidler in 1992, they believe that a case-based approach can be adopted to make decisions under uncertain scenarios, and propose an initial CBDT model [2]. CBDT divides cases into three aspects: Problem, Act and Result. And it also introduces three important concepts: Similarity, Utility Level and Aspiration Level. Respectively, they are used to measure the similarity between the current and the past two cases, the utility level of the past cases using the scheme and the overall expectation level after the adoption of the scheme. The Aspiration Level is the sum of the product of similarity degree and utility level, which is the decision basis of CBDT [3]. The final choice of CBDT decision makers is to adopt the scheme that maximizes the expectation level. Meanwhile, there are properties (hypothesis) of comparability, monotonicity, continuity, independence and invariability of similarity degree in CBDT model [1]-[7].

If the past solution has an impact on the evaluation of the current decision cases, it is necessary to introduce the "Problem-Act Pairs", with the requirement of comparing the current Problem with the solution as a whole with the past case when calculating the degree of similarity. If the decision maker has already guessed each result in the case, the similarity of the results needs to be taken into account. In some cases, the implementation scheme accomplishes not only the immediate results, but also the possible completion of the next scheme. At this point, CBDT is extended to accomplish the Case-Based Planning. In order to preferably measure the similarity among cases and make more accurate decisions, the basic CBDT model also derived two transformations: Averaged Similarity and Act Similarity [3] [4]. The Utility can be measured in two ways: the outcome tradeoff approach and the case repetition approach [5].

Gilboa and Schmeidler (1996) thought that there were two attributes of Aspiration Level adjustment rules: Realistic and Ambitious. The attributes of Realistic have the following characteristics: The Aspiration Level will be adjusted according to the actual performance; The adjustment conforms to the principle of "adaptability"; Adjusting the level of expectation is "optimal" in a sense. Ambitious has two meanings: Static Ambition and Dynamic Ambition. Static Ambition sets the initial level of expectations relatively high depending on the context; Dynamic Ambition means that decision makers never lose hope and the cycle of 
expectation level updates never stops. Gilboa and Schmeidler believe that the Aspiration Level should be realistic and dynamic ambitious, because realistic will make the Aspiration Level converge to the local optimal, and dynamic ambition plays the role of "noise", which will make decision makers choose actions that seem inferior, but converge to the global optimal in the long run [4].

Zeng et al. (2007) thought that each different Action had different impacts on decision-making and should be given different Weights. Based on this, they proposed the concept of Case Similarity with Alterable Weights and tested the technical status of cars in accidents [8].

Despite its realistic adequacy, CBDT has not been empirically tested frequently, especially in the case of repeated decisions [9]. Therefore, CBDT needs to be constantly improved and normalized, both theoretically and practically. Ossadnik et al. (2012) conducted an experiment with colored spheres to empirically analyze the CBDT theory, and the results showed that the decision-making of CBDT was highly effective, which also verified the adequacy of CBDT in reality in the case of repeated decision-making with unknown structure [9] [10]. Grosskopf et al. (2015) accomplished the experiment of monopolistic decision-making with extremely limited information in the CBR (Case-Based Reasoning) and CBDT situations respectively, and the results support the prediction of CBDT, especially in the case that timely feedback cannot be achieved [11]. Pape and Kurtz (2013) tested the efficacy of CBDT by using a set of benchmark questions from psychological experiments of human classified learning (Shepard et al., 1961) [12]. The results showed that CBDT could accurately predict these problems and empirically tested the effectiveness of CBDT [13]. Guilfoos and Pape (2016) applied CBDT to the repeated prisoner's dilemma problem to predict people's cooperative behavior, which empirically tested CBDT [14]. Bleichrodt et al. (2017) verified the observability and falsifiability of CBDT through two real estate investment cases [15]. Kinjo et al. $(2014,2017)$ believed that under certain assumptions, CBDM (case-based Decision Model) could be converted into IPM (Idea Point Model), which was verified by data from Japanese TV series, and the results were quite consistent [16] [17]. Zhou et al. (2003) proposed a double-layer CBDT fuzzy decision making method based on probability theory and case-based reasoning, and used the case of movie watching decision to verify it [18]. Han et al. (2016) proposed a mixed multi-attribute case decision method based on Regret Theory, and verified the rationality of the method by using the PX project case [19]. Krause (2009) proposed an improved model of CBDT, that is, people can make decisions based on their past experiences and those of their neighbors, and its effectiveness was tested by Monte Carlo Model [20].

\section{The Application Area of CBDT}

CBDT is currently used in a wide range of fields, such as social learning, customer theory, product theory, new product development, emergency manage- 
ment, financial market and so on.

Blonski (1999) introduced CBDT into the field of Social Learning. In his model, similarity represents social structure, and he tested the effect of social structure in the process of selecting the best. The results showed that different similarity functions represent different stable states which can positively or negatively affect the process of Social Learning [21].

Gilboa and Schmeidler (1993, 1997), Gilboa and Pazgal (2001) introduced CDBT into Customer Theory. Gilboa and Schmeidler (1993) proposed the Case-Based Consumer Theory. They found that when the aspiration level is relatively low, customers tend to choose the corner solution (non-optimal solution) because they take satisfactory decisions. When the expectation level is high, customers will keep switching between products, and their relative frequency will converge to an internal point [22]. Gilboa and Schmeidler (1997) showed that if the degree of similarity between products is positive, it means that these two products are complementary to each other; on the contrary, if the degree of similarity is negative, it means that these two products are substitutes for each other [23]. Gilboa and Pazgal (2001) used a random utility function, and their study found that high expectation level would lead to brand switching behavior [24].

Eichberger, Guerdjikova (2011), Malik et al. (2010) brought CBDT into the field of climate change. Eichberger and Guerdjikova (2011) constructed a technical adaptation model for climate change [25]. In Malik et al. (2010)'s study, CBDT is used to make policy decisions in the context of climate change, and even how individuals use past experience to make decisions in the context of climate change, such as farmers planting trees, etc. [26].

Jahnke et al. (2005) applied CBDT to Production Theory. In their paper, the company needs to make decisions on product price and production capacity in the case of distorted demand function or lack of cognition of demand function. Jahnke et al. constructed an adaptive decision-making process based on CBDT and finally verified that the decision maker would eventually find the optimal solution [27].

Some scholars have also applied CBDT to the field of new product development and product conceptual design. Li (2015) et al. introduced CBDT into the optimization of risk response schemes for new product projects, and verified it with an example of a steel company developing high-grade marine steel plate [28]. Hu (2013) combined CBDT with TRIZ theory. CBDT can be used as the case base according to the contradiction matrix in TRIZ, so as to make better decisions [29]. Wang et al. (2009, 2010) introduced CBDT into the field of product conceptual design and made an empirical analysis of cases of motorcycle engine design [30] [31] [32].

Some scholars have also applied CBDT to the field of emergency. Cao et al. (2016) introduced CBDT into the emergency contingency plan, and gave an example of typhoon landing considering the emergency effect and cost [33]. Li et 
al. (2014) applied CBDT to the selection of emergency plan for gas explosion in coal mine [34].

Guerdjikova $(2004,2005)$ introduced CBDT into financial markets, and his main concern was the choice of portfolio and asset price. For a case-based investor with endogenous memory whose expectation level is "realistic and ambitious" (Gilboa \& Schmeidler, 1996) [4], his similarity function is concave, which can always adopt an optimal portfolio [35] [36] [37] [38].

Other applications focus on road transportation, accident identification and other fields. Zeng et al. $(2009,2012)$ established an early warning system for road transport enterprise operation by using CBDT, which can provide Suggestions to enterprise decision makers [39] [40]. Zeng et al. $(2008,2009)$ used CBDT to establish an intelligent identification system for the technical status of vehicles in accidents, which provided help for the technical identification of traffic accidents [41] [42].

\section{The Research Status and Prospect of Venture Capital Project Evaluation Method}

There are many researches on venture capital project evaluation in academic circles. There are also many studies on evaluation methods, such as Risk Matrix, Fuzzy Comprehensive Evaluation Method, Analytic Hierarchy Process, Neural Network, Principal Component Analysis, Matter-Source Model and so on. These methods evaluate the venture capital projects from some quantitative or qualitative perspectives to construct the evaluation system or decision-making analysis method, so as to guide people to preferably evaluate the venture capital projects. However, these methods still have various limitations and defects among venture capital projects with high uncertainty and little information. Dang et al. (2006) studied the risk assessment of venture capital projects and believed that the method of risk matrix could be adopted. Based on this, the risk matrix of venture capital project assessment was constructed and the basic process of applying this method was designed [43]. However, the risk matrix needs to judge the risk impact and the probability of risk occurrence, which has certain subjectivity and inaccuracy. Teng et al. (2017) studied the risk assessment of private equity investment projects and believed that the risk assessment system could be constructed by using the Analytic Hierarchy Process (AHP) and Fuzzy Comprehensive Evaluation Method [44]. Qi (2008) proposed an evaluation system by AHP method, and applied the system to ITAT venture capital projects [45]. Rostamzadeh et al. (2014) used the fuzzy comprehensive evaluation method that can be used for multi-objective decision making to help angel investors make investment decisions [46]. Nevertheless, Fuzzy Comprehensive Evaluation and AHP method need to score each index; the score itself is subjectivity to some extent. Yu (2005) adopted BP neural network method and proposed a risk assessment model based on BP neural network [47]. Sun (2009) established a risk investment evaluation system based on BP neural network [48]. However, BP 
neural network method also needs to input the risk assessment of the project in advance to make better decisions. Pan et al. (2004) applied the Principal Component Analysis (PCA) method in the evaluation of venture capital projects [49]. However, PCA also needs to input the judgment of project risk before clustering. Meng et al. (2013) established venture capital project risk assessment model based on Matter-Element Model and conducted empirical analysis. The results showed that matter-element model could be effectively applied in venture capital field [50]. Nevertheless, the Matter-Element Model also needs to learn about the evaluation project, the specific risk and the degree of risk to evaluate the venture capital project. Wang et al. (2002) proposed Expected Commercial Value (ECV) method and established a decision model with ECV method as the core for venture capital projects [51] [52]. However, ECV method may be biased due to the subjectivity of index weight calculation and the inaccuracy of the calculation of discount rate selection.

Therefore, it is necessary to find a way to make better decisions with little information. And CBDT meets this need. CBDT can make "bounded rationality" satisfactory decisions even when the possibility or state is not significant. It does not need specific information of all projects given at the beginning, but only requires the decision maker to know some projects he has made in the past, so as to judge new projects and make relatively satisfactory decisions. It better reflects the thinking process of people when making decisions. Therefore, it can be applied more appropriately in the field of venture capital project evaluation. To sum up, CBDT is more general in the decision-making process, especially in the field of venture capital with high uncertainty and little information. Therefore, the application of CBDT in the field of venture capital has good research significance and application value, and this is also a good extension and improvement of CBDT theory.

\section{Conflicts of Interest}

The author declares no conflicts of interest regarding the publication of this paper.

\section{References}

[1] Liu, J.Y. and Zhang, S.M. (2015) Review on Behavioral Decision-Making Theory in Uncertain Environment. Systems Engineering, 2, 110-117.

[2] Gilboa, I. and Schmeidler, D. (1992) Case-Based Decision Theory. Discussion Paper No.994, Northwest University, Evanston.

[3] Gilboa, I. and Schmeidler, D. (1995) Case-Based Decision Theory. Quarterly Journal of Economics, 110, 605-639. https://doi.org/10.2307/2946694

[4] Gilboa, I. and Schmeidler, D. (1996) Case-Based Optimization. Games and Economic Behavior, 15, 1-26. https://doi.org/10.1006/game.1996.0056

[5] Gilboa, I. and Schmeidler, D. (2000) Utility in Case-Based Decision Theory. Journal of Economic Theory, 105, 483-502. https://doi.org/10.1006/jeth.2001.2858

[6] Gilboa, I. and Schmeidler, D. (1999) A Note on Utility in Case-Based Decision 
Theory. Working Paper No. 31-99.

[7] Gilboa, I. and Schmeidler, D. (1997) Act Similarity in Case-Based Decision Theory. Economic Theory, 9, 47-61. https://doi.org/10.1007/BF01213442

[8] Zeng, C., Xu, Y. and Xie, W. (2007) Decision-Making Based on Case Similarity with Alterable Weights. International Conference on Fuzzy Systems \& Knowledge Discovery, 1, 752-756. https://doi.org/10.1109/FSKD.2007.239

[9] Ossadnik, W., Wilmsmann, D. and Niemann, B. (2013) Experimental Evidence on Case-Based Decision Theory. Theory \& Decision, 75, 211-232.

https://doi.org/10.1007/s11238-012-9333-4

[10] Ossadnik, W. and Wilmsmann, D. (2007) Case-Based Decision Theory: An Experimental Report. Operations Research, Proceedings 2007, Selected Papers of the International Conference of the German Operations Research Society, DBLP, 5-7 September 2007, 323-328.

[11] Grosskopf, B., Sarin, R. and Watson, E. (2015) An Experiment on Case-Based Decision Making. Theory \& Decision, 79, 639-666.

https://doi.org/10.1007/s11238-015-9492-1

[12] Shepard, R.N., Hovland, C.I. and Jenkins, H.M. (1961) Learning and Memorization of Classifications. Psychological Monographs General \& Applied, 75, 1-42. https://doi.org/10.1037/h0093825

[13] DuusPape, A. and Kurtz, K.J. (2013) Evaluating Case-Based Decision Theory: Predicting Empirical Patterns of Human Classification Learning. Games and Economic Behavior, 82, 52-65. https://doi.org/10.1016/j.geb.2013.06.010

[14] Guilfoos, T. and DuusPape, A. (2015) Predicting Human Cooperation in The Prisoner's Dilemma Using Case-Based Decision Theory. Theory \& Decision, 80, 1-32. https://doi.org/10.1007/s11238-015-9495-y

[15] Bleichrodt, H., Filko, M., Kothiyal, A. and Wakker, P.P. (2017) Making Cased-Based Decision Theory Directly Observable. American Economic Journal Microeconomics, 9, 1-43. https://doi.org/10.1257/mic.20150172

[16] Kinjo, K. and Ebina, T. (2017) Case-Based Decision Model Matches Ideal Point Model: Application to Marketing Decision Support System. Journal of Intelligent Information Systems, 1-22.

[17] Kinjo, K. and Sugawara, S. (2014) Case-Based Consumer Theory. CIRJE-F-940.

[18] Zhou, K., Feng, S., Mo, Z. and Tang, C. (2003) Case Decision Method for Solving Generalized Uncertain Decision Problem. Control and Decision, 18, 181-184.

[19] Han, J., Ye, S., Chai, J. and Li, J. (2016) Hybrid Multi-Attribute Case Decision Method Based on Regret Theory. Chinese Management Science, 24, 108-116.

[20] Krause, A. (2009) Learning and Herding Using Case-Based Decisions with Local Interactions. IEEE Transactions on Systems, Man and Cybernetics Part A: Systems and Humans, 39, 662-669. https://doi.org/10.1109/TSMCA.2009.2014542

[21] Matthias, B. (1999) Social Learning with Case-Based Decisions. Journal of Economic Behavior and Organization, 38, 59-77. https://doi.org/10.1016/S0167-2681(98)00122-X

[22] Gilboa, I. and Schmeidler, D. (1993) Case-Based Consumer Theory. Discussion Paper No. 1025, Northwest University, Evanston.

[23] Gilboa, I. and Schmeidler, D. (1997) Cumulative Utility Consumer Theory. Journal of Economic Behavior and Organization, 38, 737-761.

[24] Gilboa, I. and Pazgal, A. (2001) Cumulative Discrete Choice. Marketing Letters, 12, 
119-130. https://doi.org/10.1023/A:1011134718403

[25] Malik, A., Rothbaum, J. and Smith, S.C. (2010) Climate Change, Uncertainty, and Decision-Making. IIEP Working Paper 2010-24.

[26] Eichberger, J. and Guerdjikova, A. (2012) Technology Adoption and Adaption to Climate Change-A Case-Based Approach. Climate Change Economics, 3, Article ID: 1250007. https://doi.org/10.1142/S2010007812500078

[27] Jahnke, H., Chwolka, A. and Simons, D. (2005) Coordinating Service-Sensitive Demand and Capacity by Adaptive Decision Making-An Application of the Case-Based Decision Theory. Decision Sciences, 36, 1-32. https://doi.org/10.1111/j.1540-5915.2005.00064.x

[28] Li, Y., Chen, X., Zhang, Y. and Fan, Z. (2015) CBDT Based Risk Response Method for New Product Development Project. Journal of Management Engineering, 3, 257-264.

[29] Hu, Z. (2013) Product Conceptual Design Based on Case Decision and TRIZ Knowledge. PhD Thesis, Huazhong University of Science and Technology, Wuhan.

[30] Wang, Q., Zhao, Y. and Rao, C. (2010) Case Decision Method Based on Threshold and Its Application in Innovative Design. Control and Decision, 25, 1562-1566.

[31] Wang, Q., Zhao, Y. and Rao, C. (2009) Analyses and Improvement of Case-Based Decision Model of Product Conceptual Design. Advances in Neural Networks ISNN 2009. Springer Berlin Heidelberg, Berlin, 1131-1137. https://doi.org/10.1007/978-3-642-01507-6_127

[32] Wang, Q. (2009) Research on Modeling and Decision Analysis Methods of Finite Rationality. PhD Thesis, Huazhong University of Science and Technology, Wuhan.

[33] Cao, P., Li, M. and Li, Y. (2016) Selection Method of Emergency Contingency Plan Considering Emergency Effect and Emergency Cost. Modernization of Management, 3, 102-104.

[34] Li, Y., Fan, Z. and Li, M. (2015) Case Decision Method for Solving Generalized Uncertain Decision Problem. Journal of Systems Engineering, 1, 21-29.

[35] Guerdjikova, A.V. (2004) Case-Based Decision Theory and Financial Markets. Heidelberg University, Heidelberg.

[36] Guerdjikova, A.V. (2007) Portfolio Choice and Asset Prices in an Economy Populated by Case-Based Decision Makers. SSRN Electronic Journal, 1-37.

[37] Guerdjikova, A.V. (2004) Asset Prices in an Overlapping Generations Model with Case-Based Decision Makers with Short Memory. Paper No. 04-44, SonderForschungsBereich 504.

[38] Guerdjikova, A.V. (2004) Evolution of Wealth and Asset Prices in Markets with Case-Based Investors. Paper No. 04-49, SonderForschungsBereich 504.

[39] Zeng, C., Yang, W. and Li, Q. (2009) On Intelligent Forewarning \& Decision-Supporting System for the Management of Road Transportation Enterprises. Asia-Pacific Conference on Information Processing, December 2009, 467-470.

[40] Zeng, C., Yang, W. and Li, Q. (2012) Early Warning System for Operation of Road Transport Enterprises. Highway Traffic Science and Technology, 29, 154-158.

[41] Zeng, C., Yang, W. and Li, Q. (2009) Research on Intelligent Auxiliary Identification System of Accident Vehicle Technical Status. Computer Application Research, 26, 4635-4637.

[42] Zeng, C. (2008) Research on Intelligent Identification System of Accident Vehicle Technical Status. PhD Thesis, Southwest Jiaotong University, Chengdu. 
[43] Dang, X., Huang, Z. and Zhao, Q. (2006) Risk Assessment of Venture Capital Projects Based on Risk Matrix. Science \& Technology Progress and Policy, 1, 140-143.

[44] Teng, Y., He, X. and Ni, D. (2017) Risk Assessment of Private Equity Investment Projects Based on Analytic Hierarchy Process and Fuzzy Comprehensive Evaluation-A Case Study of Three Private Equity Investment Projects. Journal of University of Electronic Science and Technology (Social Science Edition), 5, 67-73.

[45] Qi, L. (2008) Research on the Application of Analytic Hierarchy Process in Risk Assessment of ITAT Venture Capital Projects. MBA Thesis, Shanghai Jiaotong University, Shanghai.

[46] Rostamzadeh, R., Ismail, K. and Zavadskas, E.K. (2014) Multi Criteria Decision Making for Assisting Business Angels in Investment. Technological \& Economic Development of Economy, 20, 696-720. https://doi.org/10.3846/20294913.2014.984364

[47] Yu, D. (2005) Risk Investment Evaluation Model Based on BP Neural Network. Science and Technology Management Research, 9, 206-208.

[48] Sun, X. (2009) Venture Capital Evaluation System: Construction Based on Neural Network. Business Research, 11, 150-153.

[49] Pan, X., Liu, F. and Wang, Y. (2004) Evaluation Model of Venture Capital Projects Based on Principal Component Analysis. Science \& Technology Progress and Policy, 3, 65-67.

[50] Meng, L., Wang, Z. and Shen, Z. (2013) Establishment and Application of Matter-Element Model for Venture Capital Project Risk Assessment. Science and Technology Management Research, 10, 193-201.

[51] Wang, Y. and Zhu, R. (2002) Research on ECV Evaluation Index and Decision Model of Venture Capital Project. Science of Science and Management of S. \& T., 23, 52-54.

[52] Li, Y. (2007) Decision Making Method and Application Research Based on Similar Case Analysis. PhD Thesis, Northeast University, Shenyang. 